\title{
Influence of the Cognition of Student Entrepreneurs on Decision Making Based on Factor Analysis
}

\author{
https://doi.org/10.3991/ijet.v14i12.10358 \\ Shaoying Wang ${ }^{(凶)}$, Linghui Liu, Shaoyu Wang \\ Handan College, Hebei, China. \\ shaoyingw@yeah. net
}

\begin{abstract}
With the progress of science and technology, the emergence of new technologies has greatly promoted young college students' entrepreneurial boom. However, the progress of science and technology not only brings more opportunities for entrepreneurship, but also makes the market competition more intense. High-speed information updating makes the risk of entrepreneurship sharply increase. Individual entrepreneurship gradually transforms into group entrepreneurship, further increasing the complexity of decision-making. In order to reduce entrepreneurial decision-making errors, this study empirically analyzed the impact of entrepreneurial cognitive ability on entrepreneurial decision-making of entrepreneurial groups of students in Beiijing, Shanghai, Guangzhou and other regions who have been entrepreneurs for three months to six years. The data of five factors, entrepreneurial consensus ability, professional allocation ability, monitoring and control ability, decision-making speed and effect of decision making, were collected through questionnaire. The relationships between the factors were initially determined using SPSS, and the causal relationship was further analyzed using multi-variable regression analysis. The results showed that entrepreneurial consensus ability and professional allocation ability had a significant positive impact on decision-making speed, monitoring and control ability had no significant impact on decision-making speed, professional allocation ability and monitoring ability had a significant positive impact on decision-making effect, and entrepreneurial consensus ability had no significant impact on decision-making effect. In conclusion, entrepreneurial cognitive ability of student entrepreneurs has a significant impact on entrepreneurial decision-making.
\end{abstract}

Keywords-Entrepreneurial cognitive ability, speed of decision making, effect of decision making, multi-variable regression analysis.

\section{Introduction}

With the joint development of economy and science and technology, a variety of new things have sprung up, providing a lot of opportunities for independent entrepreneurship [1]. For China's economic development, self employment is one of the driving forces for its sustainable development. Moreover entrepreneurship can solve the employment problem, especially youth entrepreneurship. College students is the 
mainstream among the youth groups. For College students, the ultimate goal of entrepreneurship is to set up new enterprises. In this process, decision making directly determines the success of entrepreneurship [2]. Entrepreneurship is vulnerable to internal and external factors because of its long duration and complex process. External factors include social environment, national policies, cultural atmosphere, etc; internal factors include the number of members in entrepreneurial teams, entrepreneurial cognitive level, individual emotions, etc [3]. Peltonen et al. [4] hypothesized that individuals with higher cognitive abilities were better able in learning and accumulating new skills when exposed to different types of work and tested the hypothesis by establishing a mobile sample group which is composed of 170,000 people who took standardized intelligence tests at the age of 19 and 20 and using associated employer-employee data. The results show that cognitive ability and diverse work experiences could synergistically create useful, versatile skills that reduce the barriers to first-time entrepreneurship. Garbuio et al. [5] studied how to train students to use four mature cognitive behaviors to start an undertaking from four aspects, design cognitive research paradigm framework, analogical reasoning, deductive reasoning and psychological simulation. The teaching method was based on design cognition and emphasized creating a better environment based on the existing environment. In this study, an empirical analysis was made on the impact of entrepreneurial cognitive ability of among students who have been entrepreneurs for three months to six years in areas such as Beijing, Shanghai and Guangzhou on entrepreneurial decision-making. The data of five factors including entrepreneurial consensus ability, professional allocation ability, monitoring and control ability, decision-making speed and decision-making effect were collected through questionnaire survey. Pearson correlation coefficient method was used to preliminarily determine the relationship between the factors, and multi-variable regression analysis was used to further analyze the causal relationship; finally the influence of entrepreneurial cognitive ability on entrepreneurial decision was obtained.

\section{Theory of Entrepreneurial Decision and Impact Hypothesis}

Decision theory is based on social systematics and regards decision-making as the whole process of management. The traditional decision theory [6] takes rational economic man as the premise, and holds that people can only make limited rational decisions based on the principle of "current satisfaction" because of the limited information they can collect and utilize in decision-making management. The decisionmaking theory classifies the causes of bounded rationality constraints into the constraints of decision-makers' personal cognition and external environment, and holds that the generation process of decision-making is from thinking-cognition-decision. The whole decision-making process is divided into editing stage and evaluation stage according to the behavioral decision-making theory in this paper. Individual factors and environmental factors jointly affect the scheme coding in the editing stage, and the basic decision-making framework is constructed according to the scheme coding. In the evaluation stage, the scheme and the basic decision-making framework are 
evaluated, and the decision-making is determined according to the evaluation results [7].

Social cognitive theory is used in the behavioral decision-making model [8]. This theory mainly explains the relationship among individuals, environment and behavior, and holds that the three factors influence each other: individual factors direct the conduct, and the consequences of the behavior in turn affect individual factors, that individuals in different environments will have different reactions, i.e., different behaviors, and that behaviors can change the environment to make it adapt to individuals.

\section{Multi-Variable Regression Model}

The essential law of objective things in the real world is complex and can be affected by many factors. Moreover it is difficult for people to analyze the causal relationship of essence because of the limited observation means. In order to solve these problems, regression model, a statistical analysis model based on a large number of data, came into being. Classification of regression models is as follows:

$$
\text { Regression model }\left\{\begin{array}{c}
\text { Linear regression model }\left\{\begin{array}{c}
\text { One - variable linear regression model } \\
\text { Multi - variable linear regression model }
\end{array}\right. \\
\text { Non - linear regression model }\left\{\begin{array}{c}
\text { One - variable non - linear regression model } \\
\text { Multi - variable non - linear regression model }
\end{array}\right.
\end{array}\right.
$$

There is a correlation between variables in regression model. A large of data shows laws because of the correlation, and the laws can be expressed through function, and the function is called regression equation. The general form of regression equation [9] is:

$$
y=A_{0}+A_{1} x_{1}+A_{2} x_{2}+\cdots+A_{m} x_{m}+c
$$

where $y$ is a dependent variable, object describing law, $x$ is a independent variable, factors affecting law, $A$ is a parameter of model equation, and $c$ is a error term.

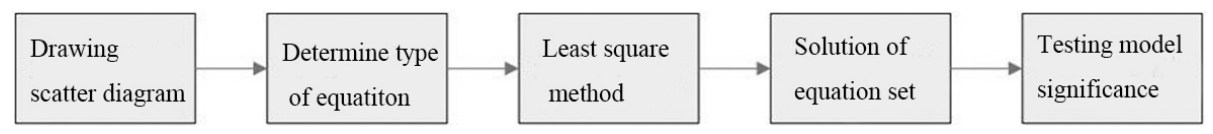

Fig. 1. The flow of establishing regression model

As shown in Fig. 3, scatter diagram is drawn according to the collected data firstly, then the type of equation is determined according to the general trend of the scatter diagram, system of normal equations is listed based on the least square method and necessary data, and finally, the system of equations is solved to obtain corresponding coefficients and error items. After the establishment of equation of regression model, significance test is needed. Correlation coefficient is tested to determine the degree of linear correlation, residual error is analyzed, and multiple factors are ranked using 
multi-variable regression equation. If the significance test of the model equation is not passed or is very poor, then another model needs to be established. The expression of analysis of variance [10] is as follows.

The sum of square of deviations of variables included in the regression model is:

$$
U=\sum_{k=1}^{n}\left(\hat{y}_{k}-\bar{y}\right)^{2}
$$

where $U$ is regression sum of squares, which reflects that dependent variable $y$ fluctuates with the changes of independent variable, $\hat{y}_{k}$ represents the value of dependent variable according to the $\mathrm{k}$-th value of independent variable of the regression equation, $\bar{y}$ represents the average value of dependent variable under all independent variables, and $\mathrm{n}$ represents the number of data collected.

The sum of square of deviations of variables not included in the regression equation is:

$$
Q=\sum_{k=1}^{n}\left(y_{k}-\hat{y}_{k}\right)^{2}
$$

where $Q$ stands for residual sum of squares, reflecting detection error, and $y_{k}$ stands for the actual detection value under the k-th independent variable.

The total deviation square sum of the equation is:

$$
S=U+Q=\sum_{k=1}^{n}\left(y_{k}-\bar{y}\right)^{2}
$$

where $S$ is the total deviation square sum.

Testing of the total regression of the equation can also be expressed as dimensionless indicator:

$$
R^{2}=\frac{U}{S}
$$

where $R^{2}$ stands for the proportion of variance of independent variable in the total deviation square sum, which can be used for representing the correlation between independent variable and dependent variable. The value of $R$ is between 0 and 1 . The larger the correlation, the better the regression.

Whether there is a linear relationship between independent variable and dependent variable can be detected using $\mathrm{F}$ test, and its expression is:

$$
F=\frac{U(n-m-1)}{Q m}
$$


where $m$ is the number of variable, i.e., the degree of freedom of regression. Variance ratio $F$ obeys $F$ distribution whose degree of freedom is (m, n-m-1). According to the given test confidence $\alpha$, the variance $F_{\alpha}$ under that confidence level can be obtained by querying $\mathrm{F}$ distribution table. When $F>F_{\alpha}$, the regression effect of the equation is significant.

The research framework of this study is the impact of entrepreneurial cognitive ability on entrepreneurial decision-making. The entrepreneurial cognitive ability includes entrepreneurial consensus ability, professional allocation ability and monitoring and control ability; the judgment indicators of entrepreneurial decision-making are decision-making speed and decision-making effect. That is to say, the impact on entrepreneurial decision-making involves multiple factors, and moreover different influencing factors have different influence degree. It is one-sided to consider the influence of single factor on entrepreneurial decision-making, and it is unable to correctly evaluate the impact of entrepreneurial cognitive ability on decision-making. Multivariate regression analysis is a statistical method that takes a large number of factors into account simultaneously. It constructs a multivariate regression equation according to most of the influencing factors and measures the deviation degree of different factors according to the multivariate regression equation.

\section{$4 \quad$ Empirical Analysis}

\subsection{Collection of sample data}

Relevant data were collected by means of questionnaire survey [11]. The steps are as follows.

The first step was designing the questionnaire, which includes the basic information of student team and enterprise, the cognitive ability of entrepreneurs and entrepreneurship decision-making information. The evaluation of cognitive ability and entrepreneurship decision-making adopted a 10-point system.

The second step is distributing questionnaires for investigation. The basic information of the subjects is shown in Table 1. The ways to distribute the questionnaires included field research with paper questionnaires, sending questionnaires by e-mail through the enterprise contact method given by government departments, and making the same network questionnaire on the network platform to conduct research in the form of forwarding.

The survey lasted for one year after the questionnaire was sent out. The collected questionnaires were preliminarily screened, and the questionnaires which were filled out with irregular and inadequate information were eliminated.

Independent sample t-test was carried out on the samples to ensure that there was no significant difference among the samples collected by the three ways and that they can be mixed.

Following the above steps, 516 questionnaires were collected and 451 valid questionnaires were screened. It was confirmed that by independent sample $t$ test [12] that 
no significant difference between the questionnaires collected by the three approaches.

Table 1. The basic data of the objects

\begin{tabular}{|l|c|l|l|l|}
\hline Research objects & \multicolumn{1}{|c|}{ Years } & Scale & $\begin{array}{c}\text { Nature of enter- } \\
\text { prise }\end{array}$ & \multicolumn{1}{c|}{ Region } \\
\hline $\begin{array}{l}\text { Student entrepreneur } \\
\text { team }\end{array}$ & 3 months $\sim 6$ years & $\begin{array}{l}\text { Middle and small- } \\
\text { sized enterprises }\end{array}$ & High-tech field & $\begin{array}{l}\text { Beijing, Shanghai, } \\
\text { Guangzhou, etc. }\end{array}$ \\
\hline
\end{tabular}

\subsection{Statistical analysis}

Firstly, SPSS [13] was used to analyze the variables, entrepreneurial consensus ability, professional allocation ability, monitoring and control ability, decision-making speed and decision-making effect. Then the multi-variable regression method was used to verify the hypothesis. Firstly, the above variables were given centralized treatment to reduce the problem of multicollinearity of multi-variable regression afterwards. The treatment formula [14] was:

$$
F_{i}=\frac{X_{i}-X_{i \min }}{X_{i \max }-X_{i \min }}
$$

where $F_{i}$ stands for the value of the i-th variable after centralized treatment and

$X_{i}, X_{i \text { min }}, X_{i \max }$ are the $\mathrm{i}$-th variable, the minimum value of the $\mathrm{i}$-th variable and the maximum value of the $\mathrm{i}$-th variable respectively.

The linear relationship between entrepreneurial cognitive ability and entrepreneurial decision was determined by Pearson correlation coefficient method, and the calculation formula [15] was:

$$
\rho=\frac{\operatorname{cov}(X, Y)}{\sigma_{X} \sigma_{Y}}
$$

Where $\rho$ is Pearson correlation coefficient, $\operatorname{cov}(X, Y)$ is the covariance between two variables, and $\sigma$ is the standard deviation of corresponding variable.

Then the impact of cognitive ability on entrepreneurial decision was further verified using multivariate regression method. Firstly the basic information of the investigation subjects were introduced into the regression equation as independent variables, and regression analysis was made on the basic information of the decision-making speed. Then the cognitive ability was introduced to the regression equation as independent variables, and regression analysis was made on the cognitive ability and decision-making speed. Regression analysis for the decision-making effect was made in the same way. 


\subsection{Analysis results}

Correlation between variables: As shown in Table 2, "**" denotes that $\mathrm{p}<0.01$, that is, the variation trend and amplitude of two variables are related. Entrepreneurial consensus ability and decision-making speed were positively correlated; professional allocation ability was positively correlated to the speed and effect of decision making; monitoring and control ability was positively correlated to the speed and effect of decision making. The findings were basically consistent with the assumptions proposed in this paper, but the causal relationships between the variables were not clear.

Table 2. The coefficient of correlation between the variables

\begin{tabular}{|l|c|c|c|c|c|}
\hline & $\begin{array}{c}\text { Entrepreneurial } \\
\text { consensus ability }\end{array}$ & $\begin{array}{c}\text { Professional } \\
\text { allocation ability }\end{array}$ & $\begin{array}{c}\text { Monitoring and } \\
\text { control ability }\end{array}$ & $\begin{array}{c}\text { Speed of } \\
\text { decision } \\
\text { making }\end{array}$ & $\begin{array}{c}\text { Effect of } \\
\text { decision } \\
\text { making }\end{array}$ \\
\hline $\begin{array}{l}\text { Entrepreneurial } \\
\text { consensus ability }\end{array}$ & 1 & & & & \\
\hline $\begin{array}{l}\text { Professional alloca- } \\
\text { tion ability }\end{array}$ & 0.061 & 1 & & & \\
\hline $\begin{array}{l}\text { Monitoring and } \\
\text { control ability }\end{array}$ & -0.046 & $0.324^{* *}$ & & & \\
\hline $\begin{array}{l}\text { Speed of decision } \\
\text { making }\end{array}$ & $0.254^{* *}$ & $0.358^{* *}$ & $0.144^{* *}$ & & \\
\hline $\begin{array}{l}\text { Effect of decision } \\
\text { making }\end{array}$ & 0.051 & $0.362^{* *}$ & $0.262^{* *}$ & $0.256^{* *}$ & 1 \\
\hline
\end{tabular}

Note: $* *$ indicated $\mathrm{p}<0.01$

Testing results of hypothesis: The influence of cognitive ability of entrepreneurial team on the speed of decision making As shown in Table 3, R2 is the ratio of the sum of squares of regression squares to the sum of squares of total deviations. The larger the value of R2, the larger the proportion of variable which can be explained by regression sum of squares in the sum of squares of total deviations, the more accurate the model and the more significant the regression effect. F-change is about the significance test of regression equation, representing making an inference on the linear coefficient between explained variable and explanatory variables. D-W test is used for testing the autocorrelation of variables; the autocorrelation is smaller when the result of D-W test is close to 2 .

Model 1 reflects the causal relationship between the number of members, age of entrepreneurial team, income of enterprise and speed of decision making. The regression results showed that the value of $p$ between the three variables and speed of decision making was greater than 0.05 , i.e., there was no significant causal relationship between the three variables and speed of decision making. On the basis of model 1, three variables of entrepreneurial cognitive ability were introduced to form model 2 . Compared with model 1, R2 and R2 obtained after adjustment were significantly improved, the fitting degree of the model was greatly improved, and the explanatory power was stronger. The regression results of model 2 showed that the values of $p$ 
Table 3. The regression analysis on the influence of cognitive ability of student entrepreneurial team on the speed of decision making

\begin{tabular}{|l|c|c|}
\hline \multicolumn{1}{|c|}{ Variable } & Model 1 & Model 2 \\
\hline Number of members & -0.049 & -0.021 \\
\hline Age of entrepreneurial team & 0.015 & -0.007 \\
\hline Income of enterprise & 0.050 & 0.060 \\
\hline Entrepreneurial consensus ability & & $0.235^{* * *}$ \\
\hline Professional allocation ability & & $0.329^{* * *}$ \\
\hline Monitoring and control ability & & 0.049 \\
\hline Constant term & & $11.548^{* * *}$ \\
\hline $\mathrm{R}^{2}$ & 0.005 & 0.188 \\
\hline $\mathrm{R}^{2}$ after adjustment & -0.006 & 0.172 \\
\hline F-change & 0.440 & $11.796^{* * *}$ \\
\hline $\mathrm{D}-\mathrm{W}$ test & 1.922 & 1.924 \\
\hline
\end{tabular}

Note: $* *$ indicated $\mathrm{p}<0.01$ and $* * *$ indicated $\mathrm{p}<0.001$.

between entrepreneurial consensus ability and professional allocation ability and between entrepreneurial consensus ability and decision-making speed were both smaller than 0.001 , i.e., the two variables had a significant impact on speed of decision making. Monitoring and control ability had insignificant impact on speed of decision making. According to the data of model 2, entrepreneurial consensus ability and professional allocation ability were included in the regression equation of model 2; therefore the equation of the influence of team cognitive ability on speed of decision making is: speed of decision making $=0.235 \times$ entrepreneurial consensus ability $+0.329 \times$ professional allocation ability +11.548 .

It could be concluded that entrepreneurial consensus ability could promote the team to produce a collective mental model which could make members have a consistent understanding of entrepreneurship and strengthen team cohesion, thereby improving the speed of decision making; professional allocation ability could promote the team to generate a coordinated mental model which could make team members effectively recognize the internal information distribution and improve utilization rate of resources, thereby accelerating decision making. The reason why the ability of monitoring and control could not have a significant impact on the speed of decision making might be that the strong monitoring and control ability made the reflexive mental model produce frequent reflexive adjustment, which enhanced the self doubt of the team and affect decision making. Generally speaking, the cognitive ability of students' entrepreneurial team can significantly affect speed of decision making, and especially the entrepreneurial consensus ability and professional allocation ability have a positive impact.

The influence of cognitive ability of entrepreneurial team on the effect of decision making: As shown in Table 4, mode 3 reflects the causal relationship between variables such as number of member, age of entrepreneur team and income of enterprise and effect of decision making. The regression results showed that the value of $\mathrm{p}$ between the three variables and effect of decision making was greater than 0.05 , i.e., there was no significant causal relationship between the three variables and effect of decision making. On the basis of model 3, three variables of entrepreneurial cognitive 
ability were introduced to form model 4. Compared with model 3, R2 and R2 obtained after adjustment were significantly improved, the fitting degree of the model was greatly improved, and the explanatory power was stronger. The regression results of model 4 showed that the values of $p$ between professional allocation ability and effect of decision making and between monitoring and control ability and effect of decision making were both smaller than 0.001 , i.e., the two variables had a significant impact on effect of decision making. Entrepreneurial consensus ability had insignificant impact on effect of decision making. According to the data of model 4, professional allocation ability and monitoring and control ability were included in the regression equation of model 4; therefore the equation of the influence of team cognitive ability on the effect of decision making is: effect of decision making $=0.307 \times$ entrepreneurial consensus ability $+0.169 \times$ professional allocation ability +12.356 .

Table 4. The regression analysis on the influence of cognitive ability of student entrepreneurial team on effect of decision making

\begin{tabular}{|l|c|c|}
\hline \multicolumn{1}{|c|}{ Variable } & Model 3 & Model 4 \\
\hline Number of members & -0.021 & 0.030 \\
\hline Age entrepreneurial team & 0.085 & 0.065 \\
\hline Income of enterprise & 0.016 & 0.031 \\
\hline Entrepreneurial consensus ability & & 0.039 \\
\hline Professional allocation ability & & $0.307^{* * *}$ \\
\hline Monitoring and control ability & & $0.169^{* *}$ \\
\hline Constant item & & $12.356^{* * *}$ \\
\hline $\mathrm{R}^{2}$ & 0.009 & 0.165 \\
\hline $\mathrm{R}^{2}$ after adjustment & -0.003 & 0.149 \\
\hline F-change & 0.819 & $10.086^{* * *}$ \\
\hline $\mathrm{D}$-W test & 1.979 & 2.018 \\
\hline
\end{tabular}

** indicated $\mathrm{p}<0.01$ and $* * *$ indicated $\mathrm{p}<0.001$.

It was concluded that the three variables of cognitive ability of team had different levels of significant influence on the effect of decision making. Entrepreneurial consensus ability had insignificant impact on effect of decision making because strong cognitive ability could lead to high cognitive coherence of a team and increase the difficulty of inputting diversified information, which might amplify the original errors in cognition and result in failure of decision making. Professional allocation ability focused on the cognitive processing of information, and new viewpoint generated in that process to ensure the correctness of decision making. Monitoring and control ability enabled the team to actively make feedback on changes in the internal and external environment, modify decision making, and improve the effectiveness of decision making. Generally speaking, the cognitive ability of students' entrepreneurial team can significantly affect effect of decision making, and especially the monitoring and regulation ability and professional allocation ability have a positive impact. 


\section{Conclusion}

This study made an empirical analysis on the impact of entrepreneurial cognitive ability on entrepreneurial decision making of students who have been entrepreneurs for three months to six years in areas such as Beijing, Shanghai and Guangzhou. Firstly, a questionnaire survey was conducted in three forms, paper, e-mail and online. A total of 451 valid questionnaires were collected and processed by independent sample t-test. After confirming that the questionnaire data could be used for general purpose, SPSS was used to test the correlation among entrepreneurial consensus ability, professional allocation ability, monitoring and control ability and speed and effect of decision making, and then the causal relationship between the above factors was verified by multi-variable regression method. It was found that entrepreneurial consensus ability and decision-making speed were positively correlated; professional allocation ability and speed and effect of decision making were positively correlated; monitoring and control ability and speed and effect of decision making were positively correlated. The regression equations were obtained through multi-variable regression method: speed of decision making $=0.235 \times$ entrepreneurial consensus ability $+0.329 \times$ professional allocation ability +11.548 and effect of decision making $=0.307 \times$ professional allocation ability $+0.169 \times$ monitoring and control ability +12.356 .

\section{References}

[1] Rönnlund, M., Sundström, A., Nilsson, L. G. (2015). Interindividual differences in general cognitive ability from age 18 to age 65 years are extremely stable and strongly associated with working memory capacity. Intelligence, 53:59-64. https://doi.org/10.1016/j.intell.2015.08.011

[2] Stienstra, M. R., Singaram, I., Ehrenhard, M. L. (2015). One Size Fits All? The Role of Cognitive Styles in Teaching Entrepreneurial Decision-making for Novices.

[3] Cadet, B, Mejia, A. G., Cuadrado-Gordillo, I. (2016). Establishing Ethical Values in Entrepreneurial Decision Making: The Justification for a Cognitive Network. https://doi.org/10.1007/978-3-319-28134-6 16

[4] Peltonen, J., Arenius, P. (2016). "Work Experience Diversity, Cognitive Ability, and First Entry into Entrepreneurship". Academy of Management Annual Meeting Proceedings, 2016(1):11132. https://doi.org/10.5465/ambpp.2016.11132abstract

[5] Garbuio, M., Dong, A., Lin, N., et al. (2017). Demystifying the Genius of Entrepreneurship: How Design Cognition Can Help Create the Next Generation of Entrepreneurs. Academy of Management Learning \& Education, 17(1):amle.2016.0040. https://doi.org/10.5465/amle.2016.0040

[6] Oo, P. P., Sahaym, A., Juasrikul, S., et al. (2018). The interplay of entrepreneurship education and national cultures in entrepreneurial activity: a social cognitive perspective. Journal of International Entrepreneurship, 2018(3):1-23. https://doi.org/10.1007/s10843-018-02294

[7] Baporikar, N. (2017). Societal influence on the cognitive aspects of entrepreneurship. 2(4):1-15. 
[8] Roessler, M., Velamuri, V. K., Schneckenberg, D. (2018). Corporate entrepreneurship initiatives: Antagonizing cognitive biases in business model design. R \& D Management. https://doi.org/10.1111/radm.12340

[9] Munoz, P. (2017). A Cognitive Map of Sustainable Decision-Making in Entrepreneurship: A Configurational Approach. International Journal of Entrepreneurial Behaviour \& Research, 2017(2).

[10] Harinie, L. T. (2017). Study of the Bandura's Social Cognitive Learning Theory for the Entrepreneurship Learning Process. 6(1):1. https://doi.org/10.11648/j.ss.20170601.11

[11] Sheikhalizadeh, M., Angoori, P. (2017). The Survey of Majid Sports Goods Brand Equity in Tabriz, Iran. National Conference of Entrepreneurship and Knowledge -Based Business Management.

[12] Akdoğan, R., Türküm, A. S. (2018). Insight Scale for Nonclinical University Students: Validity and Reliability Analysis. Measurement \& Evaluation in Counseling \& Development, 2018(1):1-13. https://doi.org/10.1080/07481756.2017.1413941

[13] Steyn, R. (2017). The psychometric properties of a shortened corporate entrepreneurship assessment instrument. 9(1).

[14] Hatos, A. (2015). University of Oradea), Hatos R, et al. Are Risk Attitudes and Individualism Predictors of Entrepreneurship? A Multivariate Analysis of Romanian Data. Amfiteatru Economic, 17(38):148-161.

[15] Ibrahim, O. A., Devesh, S., Ubaidullah, V. (2017). Implication of attitude of graduate students in Oman towards entrepreneurship: an empirical study. Journal of Global Entrepreneurship Research, 7(1):8. https://doi.org/10.1186/s40497-017-0066-2

\section{$7 \quad$ Authors}

Shaoying Wang, Linghui Liu, and Shaoyu Wang are with the School of Mathematics and Physics, Handan College, Handan, Hebei 056005, China (e-mail: shaoyingw@yeah.net).

Article submitted 2019-02-22. Resubmitted 2019-04-11. Final acceptance 2019-04-12. Final version published as submitted by the authors. 